\title{
Malawi's Transition and Transformation: Mirage or Reality?
}

\author{
By Disher Gladiator Pindani
}

\section{Introduction}

The thread of this paper is to assess the changes that have swept across the landscape of Malawi the past four years since the country embarked on the road to political reform in search for a democratic government that is accountable, transparent and protects basic human rights of its people. In Malawi, the two year span between the issue of the famous bishops' pastoral letter of 8th March 1992 and the May 17, 1994 General Elections has virtually transformed the entire political landscape of the country. To date, Malawi has with arguably unprecedented pride joined the ranks of 'buoyant' democratic nations of the universe without any major blood letting and largely outside the international limelight.

Malawi now enjoys a liberalised political life after three decades of repressive and ruthless rule marred by complete disrespect of established international human rights and other general legal principles. Thus the democratic elections of May 17, 1994 closed the worst epoch in Malawi's 30 years of one party dictatorial rule by Dr. Kamuzu Banda. Through tolerating no opposing views, imprisonment without trial, mysterious deaths for suspects, forced party card sales and gifts to the president, siphoning of the economic surplus from rural areas, both through the pricing systems and party taxes of various forms, both Malawians and outsiders were the second half of the 80's fully convinced that the one party regime was repressive, exploitative, and had in fact committed numerous human rights wrongs against sons and daughters of Malawi. ${ }^{1}$

The culmination of the upsurge of pressures for change was the defeat of the Life President Dr. Banda by Dr. Bakili Muluzi who assumed the reigns of governance and inaugurated a truly democratic government at least as far as the icons of democracy are concerned. Whether democratic tradition and culture is permeating the broad spectrum of the country's social fabric is a matter of debate if not subjective perception.

Having come that far, it may be of interest to take stock of the developments both positive and negative that have accompanied the hitherto unfolding new political order so a road

Dzimbiri, Lewis, Socio-cultural Engineering and the Changing Colours Among Political Elites in Malawi: Referendum and General Elections 1993-94, Social Change Seminar Paper, Chancellor College, Zomba, 1995, p. 1. 
map for the future can be chatted out, lest our democracy heads for the rocks. It is possible that regardless of changes the country has remained in a state of stagnation or near stagnation. That is to say, the changes may largely be symbolic with society leaping into the new epoch with the fundamental fabric of society squarely intact. Corollary, the changes may be deemed to have significantly reconstituted and vigorously shaken the basic foundations and core values of the Malawi nation for almost thirty years after independence. The paper, contrary to the pessimistic view, argues Malawi has achieved transition with remarkably profound transformation. It is argued then that since our democracy is young and fragile, it needs therefore proper nourishment for sustenance.

\section{Transition Period 1992-1994}

Disenchantment and disaffection with Banda's despotic and iron hand administration dates back as far as three decades ago, at least if the 1964 cabinet crisis is rendered to critical and analytical analysis. ${ }^{2}$ Once the fairly protracted independence struggle was a success story, young nationalists like Henry Chipembere, Dunduzu Chisiza, Kanyama Chiume, etc. thought time was ripe for Malawi to fully champion democratic ideals while continuously searching for and/or unlocking inherent economic, political and social potential in the ambit of a permissive and enabling environment. However, this was not to remain yet an untapped dream for nearly three decades later, for the independence honey moon was to be derailed and jeopardised by attempts of the inner circle to propagate a centralised political milieu which did not auger well with the aspirations and ideals of the young and educated compatriots. At least they were quick witted and shrewd to detect dictatorial tendencies in the preliminary phases which were to attain abhorrent proportions three decades later.

In a wider context, the collapse of communism in the Eastern bloc countries of Europe in 1989 and the publication early in March 1992 of the Malawian Catholic Bishops' Pastoral Letter, Living Our Faith, actually precipitated a final blow to the despotic Malawi Congress Party Regime. ${ }^{3}$ The demise of communism signalled bad omen for countries, Malawi inclusive, which had enjoyed preferential treatment at the peak of the cold war tussle. The donor community, which had supported Malawi staunchly during the cold war years, when especially Banda's non-confrontational stance with South Africa was a very welcome position had suddenly become critical. ${ }^{4}$ This point was driven home when, at their meeting in

Mzunda, Maatembo / Ross, Ken, Church, Law and Political Transition in Malawi 1992-1994, Mambo Press, Gweru, 1995, p. 4.

3 
Paris on May 1992, the Western donor countries decided to withhold all new non-humanitarian aid to Malawi until political leadership had improved its human rights record, instituted accountability and brought transparency to the business of government.

On the other hand, the pastoral letter, by condemning the political, social and economic injustice that had prevailed in Malawi in no uncertain terms since independence, sparked fires of untold protests by a people already tired of continued subjugation and the lack of hope for a better future: ${ }^{6}$

"In our society we are aware of a growing gap between the rich and the poor with regard to expectations, living standards and development. Many people still live in circumstances which are hardly compatible with their dignity as sons and daughters of God. Their life is a struggle for survival. At the same time a minority enjoys the fruits of development and can afford to live in luxury and wealth. We appeal for a more just and equal distribution of the nation's wealth."

The crisis was exacerbated by Chakufwa Chihana (a Trade Unionist), upon returning from a conference of exiled politicians in Lusaka convened specifically to chart out courses of action albeit liberate the country from bondage of ruthlessness, openly challenged the legitimacy of the regime. Still not prepared to give in, the government reacted by incarcerating him evoking the infamous sedition charges. ${ }^{8}$ Paradoxically, by the time of his release in June 1993, he had become for many a living symbol of the struggle against dictatorship and human rights abuses.

Apart from the catholic bishops, the donor community and Chihana, other important players were ordinary workers. Echoing the issues addressed in the pastoral letter, workers put down their tools and went onto the streets, demanding higher wages and better working conditions. They had nothing to lose, but their 'chains'; the chains being the meagre salaries which one observer called 'retainer'. The strikes swiftly degenerated into sporadic scenes of violence and looting and into an eventual confrontation between the police and Malawi Young Pioneers with ordinary Malawians. ${ }^{9}$

The government could no longer afford to hold on to its delaying tactics; it had to initiate an atmosphere of moderation and compromise albeit to accommodate plurality and diversity of political viewpoints and opinions. Failure to put in place institutional mechanisms as

\footnotetext{
5

6

The Courier, November-December 1995, p. 24.

The Courier, July-August 1995, p. 32.

7

8

Catholic Bishops, Living Our Faith, Balaka, March 1992, p. 4.

University of Malawi, CODESRIA Conference Resolutions, Zomba, 1994, p. 7.

Ibid, p. 11.
} 
conduits of concretising people's desires and aspirations would have degenerated into a situation of total anarchy with untold consequences. The result was for the government to initiate a programme of social and political reform by creating appropriate fora at which disputes and differences could be resolved by means of discussion. ${ }^{10}$ Prior to the birth of pressure groups like the Alliance for Democracy (AFORD) and United Democratic Front (UDF), the transitional process set of $f$ the ground through an umbrella organisation known as the Public Affairs Committee (PAC) which drew its membership from the religious, professional and business community, and its purpose was to act as a conduit for discussion with the government. The President responded by naming a Presidential Committee on Dialogue (PCD) for this purpose.

Similarly, as a way of putting to test the legitimacy of a one party administrative machinery, a referendum was to be held on the question of whether to retain the one party system or to adopt a multiparty system of government. This decisive event was, after protracted negotiations, slated for 14th June 1994, and its outcome served to affirm disenchantment with the political order of the day. $66 \%$ of the population voted in favour of political pluralism, whereas $33 \%$ mostly from central region, albeit stronghold of Malawi Congress Party (MCP), voted for the retention of the system.

This means that the government had no choice but to bow down to the wishes of the people. The National Consultative Committee (NCC) was established charged with the responsibility of discussing all aspects of the transition including the setting up of an Electoral Commission and defining rules for campaigning in the media. ${ }^{12}$ It also oversaw the drafting of the new constitution. It served as a forum for compromise but more importantly as the venue for the creation of democracy.

May 17, 1994 was eventually agreed on as a date for the General Elections. ${ }^{13}$ In the event, the Presidential and Parliamentary Elections followed the pattern established in the referendum. UDF dominated in the south, while MCP continued to have some following and clung to a strong heartland in the central region, whereas in the north AFORD had strength. The story of Malawi's democratisation shows regional fragmentation which was inherent in the allegedly united country i.e. the results revealed fragmentation of the polity along regionally defined political cleavages or enclaves. The diversity was forcefully

10

11

12

13
Mzunda / Ross (Fn. 2), p. 5.

van Donge (Fn. 4), p. 321.

The Courier, July-August 1995, p. 34.

For a detailed discussion of the Referendum and the Presidential and Parliamentary General Elections read Dzimbri, Lewis, The Malawi Referendum of June 1993, in: Electoral Studies (1994), Vol. 13, No. 3, pp. 229-234; and for an analysis of the voting pattern read van Donge (Fn. 4), pp. $302 \mathrm{ff}$. 
curbed, compartmentalised or destroyed under the guise of national unity and development during the one-party regime of Dr. Kamuzu Banda.

This development poses formidable challenges to the sustainability of our arguably hardwon democracy. Obviously, this must be treated as a matter of urgency and no effort must be spared in searching for working solutions to prevent the country sliding back into dictatorship. Simply stated, there is need to forge a feasible way forward and the task is incumbent upon each and every well intentioned and patriotic Malawian. I turn to this point later in the discussion of the challenges facing the young democracy in Malawi.

\section{Political Transformation}

\subsection{Political and Human Rights}

Malawians now enjoy numerous basic and inalienable human rights which four years ago were unthinkable, viz: freedom of speech, association, expression, press, assembly, opinion, conscience, belief, religion, just to mention a few. The country's second republican Constitution of 1994 - the supreme law of the land - does devote chapter four illuminating explicitly on the bill of rights, both underogable and derogable rights and circumstances permitting derogation. ${ }^{14}$ The idea of incorporating a bill of rights as outlined in internationally sanctioned human rights instruments was mooted in the 1966 constitutional proposals. However, it was brushed aside by the leadership albeit as it was perceived it would be a stumbling block to wielding powers for selfish ends.

Malawi has undeniably witnessed unprecedented relaxations on the political activities in its political history. A country that for more than thirty years was denied of any form of opposition has registered more than a dozen political parties of which Alliance for Democracy (AFORD), United Democratic Front (UDF), Malawi Congress Party (MCP), Congress for the Second Republic (CSR), Malawi Democratic Party (MDP), Malawi National Democratic Party (MNDP) are some, each party championing differing political views while forming a formidable opposition to the ruling party (UDF).

Political Parties are seen as a means of forming the political will of the people. As a result of the 1994 democratic General Elections, the 177 seats in Parliament were distributed amongst the three major political parties in Malawi: United Democratic Front - 29 seats (52\%), Malawi Congress Party - 52 seats (29,3\%) and Alliance for Democracy - 33 seats

14

The Constitution of Malawi, 16 th May 1994, Chapter 4. 
$(18,6 \%)$. Malawi is no more fallaciously construed as a homogeneous political entity ${ }^{15}$ but whose diversity can be tapped for the common good.

Surely, the nine month long parliamentary walkout of AFORD and MCP Members of Parliament (MPs) since July 1996, the reason of which was that six AFORD ministers remained in cabinet even after the break-up of the UDF/AFORD coalition, was a cause for concern to the nation. The parliamentary stalemate could possibly be understood out of political parties enjoying only a regionally based support. Had it been that there was crossregional party dominance, this situation should not have plagued our political scene. The negative impact of the boycott on the country's socio-economic progress need not be overemphasised. Since parliament had been inactive, there had certainly been unnecessary delays in transacting business whose execution awaited its sanction. Thus there is need to search for institutional mechanisms that could prevent unnecessary parliamentary walkouts in future.

Equally requiring urgent attention is the violence that has now become typical of by-elections as well as patronage campaign strategies on the part of the political parties and the defections of mostly opposition MPs to the ruling party. A casual review of the recently held by-elections reveals that violence is gradually becoming endemic, pointing to the absence of tolerance among people of differing political loyalties. The defections are seen as a result of MPs seeking personal economic and political gain at the alter of public interest, and in a poor country like Malawi by-elections are a very costly exercise. ${ }^{16}$

\subsection{Civil Society}

In a society where an active and powerful civil society has been prevented from taking root, it is encouraging to note the emergence of civil society organisations; trade unions, professional associations and an array of non-governmental organisations (NGOs) of which The Malawi Institute of Democratic and Economic Affairs (MIDEA), Malawi Carer, Women's Voice, Centre for Human Rights and Rehabilitation, Association for Progressive Women, Society for Advancement of Women, Civil Liberties Committee are some. It is generally agreed that programs run by these civil society organisations to create awareness in respect of the rights and duties of a citizen in a democratic society and aimed at strengthening the confidence of every Malawian in his/her won efforts are very crucial. The public debates initiated by MIDEA on various topics like democracy and decentralisation, and civic education championed by these civic organisations are a valuable contribution to the nour-

15

16

Chinsinga, Blessings, The Masses and Politics, in: Daily Nation, October 11, 1996.

The Electoral Commission estimates that each by-election costs about one Million Malawi Kwacha (approximately US\$ 66,666 as at 1996 exchange rates). 
ishment of democracy. More importantly, they are serving as watch dogs for potential government excess and maladministration besides steering grassroots participation in the political and development process. Thus the once exceedingly passive civil society is now vibrant raising hope for the sustainability of democracy.

However, the civil society is threatened by lack of reliable internal financing as most of them are donor-financed. Others have been accused of being biased in their "refereeing" and that political influence has infiltrated their agendas. The reliance on donor contributions in running the civil organisations and the mentality of passively waiting external solutions for internal problems are likely to impede the growth of a vibrant civil society. But one can not despair as building democracy is a formidable task that requires time.

\subsection{Information Explosion}

Of particular interest is the information explosion that Malawi has experienced. The advent of political pluralism has visibly put an end to decades of disinformation and strict media control by the state. Meanwhile, circulation of newspapers and magazines has rapidly swelled from two strongly state monitored newspapers. Daily Times and Malawi News, to almost over a dozen of newspapers and magazines like The Nation, UDF News, The Enquirer, Financial Observer, Star, The Weekly Chronicle, The Malawi Democrat, The Independent, just to mention a few. Expanding E-mail, Internet and other electronic information networks have significantly been utilised by Malawians both internal and abroad in generating exchange of news. The popular and independent Nyasanet ${ }^{17}$ has shown the power of the electronic media in the sustenance of democracy.

The burgeoning media does freely criticise the government and presidential policy let alone exposing embezzlement, corruption and maladministration in high places. Cases in point which have received rigorous media scrutiny include: the field york scandal where a minister is alleged to have by-passed the bureaucratic procedures in identifying a supplier for notebooks with an intent of receiving a kickback, the adoption of a politically neutral currency, instruction of pupils in local languages in the junior primary school, free primary

17

Nyasanet is a Cyberspace-run mailing list for things Malawian by more than 800 participants mostly Malawians studying or working abroad, friends of Malawi and those in Malawi with access to computer services. Topics discussed are varied ranging from agricultural policies, health, education, security, politics, etc. It is a useful electronic medium for distributing information rapidly. For example, Nyasanet enabled Malawians abroad to participate in the process of drafting the 1994 Malawi Constitution by commencing on the draft Constitution. 
education, etc. Thus the process, while remaining fragile ${ }^{18}$, has enabled journalists and the media in the country to exercise rights and freedoms that until 1994 were denied. Creative journalism is unfortunately hampered by the "censorship by ownership" 19 syndrome as most of the newspapers are politician-owned papers such that the papers have become a means of party propaganda.

The frontiers of academic freedom have similarly opened up. Prior to change, research, a vital function of any university, was severely hampered by a number of factors, including frequent closures of the National Archives in Zomba. No approval was given to any topic which could embarrass the government thereby rendering large areas of Malawi's political, social, cultural and economic life "out of bounds" for researchers. ${ }^{20}$

Political Science as a discipline could not be introduced as a subject to be taught at the one and only University of Malawi. Professors deemed "controversial" or teaching "subversive" material were thrown into jail or some simply went into exile. The writer has vivid memories of his student days at the University of Malawi in the late 1980s when some students were dismissed for writing articles in The Chirunga Newsletter ${ }^{21}$ that were critical of the country's leadership and its policies. Today, the then Department of Public Administration has changed its name to that of Political and Administrative Studies, signalling the centrality of Political Science in a democratic Malawi and soon students will be graduating with a Political Science degree. A culture of fear that engulfed the society is fastly getting eroded with the dawn of political pluralism.

\section{Economic Transformation}

\subsection{Economic Liberalisation and Deregulation}

Malawi's economy has similarly undergone a period of remarkable transformation first and foremost because democratisation and economic liberalisation are seen as twin reform processes that mutually reinforce each other and the ultimate success of democracy. Malawi's economy was monopolised by basically state-owned enterprises such as the Agricultural and Marketing Corporation (ADMARC); Press Corporation, Malawi Development

A sad development is the folding up of some newspapers like the Malawi Democrat, The Weekly Chronicle, The Enquirer due to limited readership (basically the $15 \%$ urban population) in a resource poor country with a literacy level of about $40 \%$.

Lwanda, John, Promises, Power, Politics and Poverty: Democratic Transition in Malawi (19611999), Glasgow, Dudu Nsomba Publications Ltd., 1997, p. 157.

20

University of Malawi, CODESRIA, 1994, p. 4.

21

Chirunga Newsletter is a Student Magazine at the University of Malawi. 
Corporation (MDC), and a few Asians. It is paradoxical that while Malawi was enjoying high growth rates in Gross Domestic Product of about $6 \%$ during the one-party rule, the same was not accompanied by the general improvement in the peoples' living standards and welfare. $^{22}$

With poverty alleviation as the hallmark of government policy, the country's economy has been liberalised; it is opened up both on the external and internal frontiers with the view to enable the poor masses actively participate in the economy, whether in trading of imported or locally manufactured, in manufacturing or in the service sectors. Economic liberalisation is thought to be associated with the efficient allocation of resources which would go a long way in minimising waste of ten associated with resource allocation that does not respond to market signals. Deregulation of the economy has opened the floodgates of vending and trading in various sectors of the economy previously tightly controlled. Today, vendors, mostly disgruntled youth, have littered nearly every corner of the commercial centres with brands of wares that could have hardly found their way into the country three or so years ago. The transport sector has notably undergone a period of significant boom. Minibuses now flood the commercial centres, forcing Stagecoach in Lilongwe (Malawi's Capital City) to withdraw its Cityline services and improve its services on the M1 road lest it loses out to its competitors. Similarly, various banks like the Finance Bank of Malawi, Commercial Union have been established offering stiff competition to the two main state-owned and(or supported banks - National Bank of Malawi and Commercial Bank of Malawi.

The liberalisation of agricultural marketing has ushered in a vast number of private traders and destroying ADMARC's monopoly over crop and input marketing. Unfortunately this has not augured well for consumer welfare since most poor people in Malawi are sensitive to even slight movements in the price level. The Privatisation Act of 1996 gave the government a go-ahead to privatise / divest state-owned enterprises. As at May 1997 eleven divestitures had been completed, and eleven more were at various states of preparation. ${ }^{23}$ Privatisation is aimed at breaking state monopoly by diversifying ownership to employees and local people with the view at redistributing wealth, generating income for the state and reducing the role of the state in the economy so it can concentrate on its core role of regulating and enabling the private and voluntary sectors to perform. Whether the benefits of economic liberalisation and privatisation will trickle down to the poor masses in Malawi Paris, May 13-14, 1997, p. 5. 
remains to be seen, for, as one commentator put it, "progress is not measured on spread sheets or in speeches, but in progress in the village and in the street." 24

\subsection{Price Decontrol}

Decontrol of prices, the cash budget system and removal of subsidies have led to differential pricing and an increase in the availability of commodities respectively (100\% in 1995). Though many basic goods and materials are available, they are beyond the means of many people in Malawi. One of the reasons for this is the deplorable wage structure which exists. Some human rights activists have argued that, if goods and services are provided at a price the average citizen can not afford, that denies the freedom to enjoy life. The floatation of the Malawi Kwacha coupled with the liberalised market reforms exacerbated inflation spirals (rising to $98 \%$ in 1994/95 which figure was brought down to $20 \%$ within a two year period) and consequently led to the considerable erosion of the purchasing power. In one way or another this development fuelled widespread industrial unrest as people attempted to index their wages to the prevailing inflation rates.

\section{Socio-cultural Transformation}

A closer review of the socio-cultural fabric of the country since transition reveals that the democratisation process has had a significant dent and is likely to continue as the democratic culture and/or tradition gets slowly entrenched. Sooner or later Malawi is likely to be characterised by a socio-cultural milieu radically different from that of a one party era.

Tides against the socio-cultural fabric have been felt in the context of the relaxation of the Censorship and Control of Entertainment Act and the repeal of the Decency in Dress Act. The Censorship and Control of Entertainment Act provided powers and discretion to the Censorship Board to ban publications, films, pictures, plays, deemed not compatible with Malawi's cultural standards: On the other hand, the Decency in Dress Act prohibited women from putting on attires that were not culturally sanctioned ${ }^{25}$ (i.e. mini-skirts and trousers). The basis for the repeal is that that was an interference with an individual's freedom of expression, access to information and women's rights to privacy and freedom.

Chair's Opening Statement by Barbara Kafka, World Bank Country Director for Angola, Malawi and Zimbabwe at the Malawi Consultative Group Meeting, Paris, May 13-14, 1997, p. 3. Research and Publications Committee Conference held at Mulangeni Holiday Resort, Mangochi, April 5-8, 1994, p. 12. 
Therefore it needs not be overemphasised that the exposure to western ideas and culture through the aforesaid relaxations has had profound impact on the social fabric of the country. However, it deserves mention that sporadic pockets of rigidity still manifest particularly in the rural enclaves of the society who fear for the erosion of cherished cultural values in favour of alien ideas.

Moral decay among the youth is becoming a topical issue particularly in the media. It appears that the youth has actually misinterpreted the exact meaning, and the ideals of democracy disregarding responsibility that freedom entails. Media reports are abound with cases of deteriorating discipline and lamentable relaxation of morals among the youth which has had negative impact on the social fabric of society. We always hear almost daily cases of students going in rampage, vandalising school property in the name of democracy. Thus the measures of discipline and moral standards of pre- and post-democratisation youths stand in a marked contrast.

Moreover, crime in form of rape, armed robbery, drug use has received media attention of late. Perhaps this can be explained in the context of the "newness" of the democratic milieu where the enormous changes sweeping across our socio-cultural milieu have overweighed people's expectations. For a people who had for the past years been denied of any breathing space, their responses are likely to be overwhelming and defy conventions. As a collorary, the disbanded Malawi Young Pioneers (a paramilitary wing of the then ruling MCP regime) and the Youth Leaguers who were used effectively in maintaining law and order have left a vacuum in the security machinery which the understaffed and poorly financed Malawi Police is failing to cope with. The booming press has done a good job at reporting crime incidents which in the past could not be disclosed for fear of "tarnishing the good image" of the country and raising unnecessary public alarm about crime.

To take the youth out of the streets and engage them in productive endeavours, the Government of Malawi's Youth Policy (1996) recognises that young Malawians "need access to credit, to numeracy, literacy, and technical skills both in and outside school" ${ }^{26}$ hence the establishment of the Youth Credit Scheme. Further the recruitment of young Malawians as National Volunteers has just began with a view of exposing the youth to work at community level and development issues. The effects of these on turning the youth into productive beings will need close monitoring as times goes by. 10. 


\section{Overcoming the Obstacles}

The task of dismantling the one party ruthless administrative apparatus has certainly been successfully accomplished. One partyism has disappeared and Malawi is a very different society from what it was under MCP rule; democratic freedoms are now abound, and democracy is gradually taking root. ${ }^{27}$ All the people regardless of their political, cultural, regional, religious, ethnic loyalties should graciously accept this eventuality and consequently spare no effort in making sure that no stone is left unturned in nurturing the new political order lest we drift back into an era of 'death and darkness'. Taking into account what has since transpired, there is every reason for us not to get contented but rather start seriously charting out possible courses of action to take us into the promised land.

\subsection{Managing Ethnic Conflict}

A possible point of departure is a critical analysis of the outcome of the May 17, 1994 poll especially how some greedy politicians have made a mess out of it. The results exposed the division of the country along regional lines. Basing on the pattern of the results it is tempting to argue that one partyism has persisted, but on a regional basis. It is certainly there in the north where AFORD is unrivalled, and there is a similar situation in a large part of the centre (MCP) and the south (UDF). While a search for consensus from within the political scene has characterised the democratisation process in Malawi as evidenced by the peaceful manner in which the threat to democracy posed by a protracted walk-out of opposition parties from Parliament was resolved, the fragmentation of the polity needs to be addressed to prevent ethnic competition from turning into ethnic battle. Recent discourse in Malawi points to the need for a proportional regime as compared to the current majoritarianism due to the stubborn nature of politicised ethnicity. Some commentators believe that by dispersing authority and victory, proportional institutions endear dissatisfied ethnic groups to the regime - that is, to the institutional status quo. They socialise them enough to prevent their use of extreme measures to engage the regime. ${ }^{28}$ The establishment of the Senate as a second Chamber of the National Assembly which was shelved by parliament till 1999 could have been a move in the right direction as it could have had representatives of District Councils, Chiefs, interest groups like women organisations, the disabled, trade unions, religion, business, health, farming, etc. 


\subsection{Strengthening the Institution of Parliament}

It can be argued that regional polarity had partly been responsible for the political paralysis that had characterised the country during the parliamentary boycott in that politicians seemed to put regional interests first. The real challenge for politicians in Malawi at present is to create a symbolic policy framework which gives direction to the country other than factional party manifestos. Such an approach, rather adversarial politics in which politicians of all parties excel could give much more impetus to bridging regional loyalties. ${ }^{29}$ This suggests the need for stepping up civic education among the governors and governed before the situation gets out of hand.

Recognising this, the Speaker of the National Assembly, Rodwell Munyenyembe, initiated a Parliamentary Training Programme in 1996, a two-year programme that intends to ensure MPs are well-informed about education for tolerance and peace, non-violence, human rights, democracy and gender issues ${ }^{30}$, from which the first group of 40 MPs has graduated in August 1998. Whether this programme will result in better informed MPs, better understanding of issues discussed in the National Assembly, fruitful and rational debate and in short the consolidation of democracy, remains to be seen in the business of the National Assembly.

As for the pervasive regional sentiments, the media and MPs have surely an exceedingly vital role to play. Media personnel must help ethnic, regional, religious, political or cultural differences to be accepted as a heritage from which everyone can benefit and not a basis of division. This can materialise of more independent papers and radio stations without any political agenda emerge and get sustained; but in a country where politicians have the means to establish such, that is likely to remain a dream. MPs have a vital role of providing civic education to their electorates. Similarly parties must learn to accept defeat, otherwise this tendency shall sooner or later erupt into uncontrollable violence.

\subsection{Continued Civic Education}

The civil society contribution to the building of a new democratic Malawi is just beginning to show fruit in a country where the repressive regime undermined visionary and futureoriented movements in favour of day-to-day security needs. Civic education becomes vital to stimulate voluntary efforts of the community and the civil society in a changed society where government is yet to take its rightful role - that of a facilitator rather than a con-

29

van Donge (Fn. 4), p. 307.

30 University of Malawi, The Malawi Parliamentary Training Programme: Evaluation of the First Training Session held between 30th September - 11 th October 1996, p. 1. 
troller. After all, with high illiteracy levels, the constitution needs to be explained to the masses so people are made aware of their rights as citizens and responsibilities to the state. Freedom is normally constrained within the limits of justice unlike the current thinking where a newly liberated people believe they are free to go to whatever limits in exercising their freedoms. Training of trainers will have to receive a lion's share of resources, if the capacity of civil society organisations is to be strengthened. Civic education will have to become a continuous process and not a one-off activity just before elections.

\section{Concluding Remarks}

Since 1992, Malawi has managed to democratise within a short time span using an intensive and consultative negotiating process. Democratic institutions that aim at consolidating democracy now abound, a free press has emerged, economic liberalisation has managed to curtail state monopoly where one sees individuals and communities actively involved in trading and other economic activities in improving their lives, participatory conflict resolution mechanisms in ending the parliamentary boycott are all encouraging signs that democratic culture is taking root. Disturbing trends are things like violence experienced at byelections, lack of tolerating opposing views as evidenced by the parliamentary walkout, the fragile press and civil society that is being chocked by partisan interests and lack of enough local funding, crime as a result of some misinterpreting the meaning of democracy, etc.

In spite of the social, economic and political mishaps Malawi is experiencing, one can not despair on the premise that our democracy is heading for the rocks, rather these should be seen as the birth pains of a democracy in the making. In short, building a democracy is a long and often difficult task. To survive, our democracy needs constitutional justice, regular elections, a simple and easy way to vote more than one political party, independent judges and courts, responsible parliament and strong opposition. Equally important are attitudes embracing respect for human rights, rejection of violence, tolerance of different opinions, commitment to talking, accountability of leaders, responsibility of citizens and accepting the results of an election. ${ }^{31}$ Just as John F. Kennedy urged his fellow Americans to think of what together they could do for the betterment and freedom of man, so is my hope that all well-intentioned Malawians will take personal responsibility in consolidating our hard won democracy. 


\section{Malawi's Transition and Transformation: Mirage or Reality?}

\section{By Disher Gladiator Pindani}

Since the issue of the Malawian Catholic Bishops' pastoral letter of March 1992 ("Living Our Faith"), leading to the General Elections of May 1994, Malawi passed an entire transformation of its political landscape. After reviewing the developments following a 30-years one-party-rule of Dr. Kamuzu Banda the paper concentrates on the aspects of the actually attained democracy standards and especially their social perspectives. It offers some interesting background informations referring also to institutional questions. Disturbing trends like lack of tolerating opposite views including accepting beyond question the result of an election, a fragile press freedom and partial labile structure of civil society are not denied. But they are considered by the author as birth pains of a democracy in the making. 